\title{
Between dirigism and laissez-faire: Effects of implementing the science policy priority for biotechnology in the Netherlands
}

\author{
Arie RIP \\ Depariment of Science Dinamics, Unitersity of Amsterdam, $1018 \mathrm{WV}$ Amsterdam, The Netherlands \\ Anton J. NEDERHOF \\ LISBON (Leiden Institute for Social Policy Research). Unicersity of Leiden. 2312 AR l.eiden. The Netherlands
}

Final version received 15 April 1986

\begin{abstract}
A Program Committee Biotechnology was established in the Netherlands for the period $1981-1985$, to stimulate biotechnological research and its contribution to innovation. Effects of its activities on researchers and on the research system have been measured in terms of recognition of and commit. ment to the priorities and approaches of the Program Committec. Results from the questionnaire survey and the interviews are presented, and are used to assess the implementation strategy of the committe and the dynamics of oricntation of researchers to new priorities. A consciously orchestrating strategy. with sone accommodation to the interests of the field, appears to be productive. This may be a generally useful middle course between dirigism and laissez-faire, because it exploits the leverage that resides in the strategies of scientists to mobilize resources for their work.
\end{abstract}

\section{Introduction}

Actual experience with implementation of science policy priorities, as well as insights from implementation studies in general, have led to a better understanding of the possibilities and limitations of implementing science policy priorities. Only rarely, however, has assessment of the effects of such implementation been undertaken. Most often, policy analysts as well as practitioners of science policy have been content to build on their own estimates of the success of the implementation when evaluating past experience and designing new implementation activities. This is one

Research Policy 15 (1986) 253-268

North-Holland reason to present the results of our recent evaluation study of the effects of stimulating biotechnology-relevant research in the Netherlands [19]. Also, we think that the findings themselves will shed some light on the interactions and processes occurring during implementation of science policy priorities.

Strategies of implementation can be usefully located on a continuum, with synoptic policy making with top-down implementation at one extreme, and purely reactive science policy (e.g. guided by proposal pressure) at the other. The former option may look attractive on paper, but is seldom realistic. The American Cancer Program has been set up this way, and analytical tools have been developed for top-down implementation in the work of German science scholars in Starnberg and Bielefeld ([5], [20], see also [15] for a brief evaluation). Even there, scientists and scientific institutions are heavily involved in articulating priorities and specifying implementation activities, transforming the program in the meantime to a shape more in accord with their interests.

Reactive science policy, on the other hand, is characterized by a generalized largesse towards science, which may have been acceptable in the "golden age" of science policy, the decade between 1957 and 1967, but is not suited to the climate of selectivity and accountability of the 1980s. As a strategy of implementation, a reactive science policy has to assume that science is a reservoir containing a wide variety of potential projects that will materialize as soon as priorities 
are set and funds are made available. Thus, it neglects existing social-institutional, as well as cognitive structures, which will limit and transform the realization of the priority.

Present practices of implementing science policy priorities try to run some middle course between the two extremes. Only when an overwhelming sense of urgency is shared among policy makers and researchers can science policy proceed by defining a mission and creating an organization for this task. In other cases commitment of scientists and their institutions has to be won, which often requires adaptations from policy makers to existing cognitive and institutional interests. In Europe even more than in the United States, realistic goals are often limited to shifting ongoing research in preferred directions.

In 1979, when biotechnological research was declared a science policy priority in the Netherlands by the Ministers of Science Policy and of Economic Affairs, they approached the implementation of the priority in the by then usual Dutch style: establish a Program Committer in which prominent scientists (and in many cases also industrialists with a scientific background) are appointed to prepare and to implement a science policy program. Thus, execution of policy is delegated to representatives of the field in question. However, members are generally selected for their identification with the mission (in this case to stimulate biotechnological research in the Netherlands with a view to creating an infrastructure for innovations). Program Committees therefore have a dual role. All this applied to the Program Committee Biotechnology (PCB), and it played both roles effectively by championing biotechnological research with the Ministries (e.g., by negotiating for larger budgets), and by orchestrating the implementation of external priorities (e.g., of big industrial corporations in the Netherlands) with the scientists.

A Program Committee faces a number of problems: it (usually) has to address a broad and heterogeneous area of research, and has to mobilize not only scientists for the specific priorities, but also existing institutions and funding agencies, each with their own stake in the field. In the case of biotechnology, the multi-actor character of the implementation situation has been especially pronounced because of the "shining future" of biotechnology (to quote a conference title), which attracts many actors to the area. This facilitates one task of the Program Committee, raising interest for the general priority, but makes it more difficult to get commitment to the specific program it develops.

The Program Committee Biotechnology has been conscious of these problems, and taken an activist approach in addressing them. For the same reason. it welcomed the opportunity. provided by the Office of Science Policy of the Ministry of Education and Sciences. to have three evaluation studies done: of the impact on scientific research, of the industrial situation. and of societal impacts of biotechnology. The results of the first of these studies will be reported here; a detailed version is available in Dutch [19]. A general impression of the program and of Dutch biotechnology activities can be found in the symposium report [11].

Many of the details of the implementation of the priority and its effects are. of course, specific to the Dutch situation and to Dutch biotechnological research. The issues of commitment of scientists to science policy program goals, and of entrenchment of priorities in the research system are of more general interest, and will be the focus of this article. For the same reason, we shall pay some attention to the methodological problems of measuring commitment and entrenchment.

\section{The Biotechnology Program and the measure- ment of its effects}

To avoid misunderstandings, we note at the outset that the definition of biotechnology (never a simple matter), tends to differ between Europe and the USA. While American usage emphasizes the applications of "new", often molecular biology. Europeans accord more weight to the technological or engineering aspects:

Biotechnology is the application of scientific and engineering principles to the processing of materials by biological agents to provide goods and services. [3]

Furthermore, the biological agents are often limited to micro-organisms, cell cultures and enzymes. The Dutch Program Committee follows the definition that has also been adopted by the European Federation of Biotechnology, and which 
specifies the relevant scientific and technological disciplines:

Biotechnology is the integrated use of biochemistry, molecular genetics, microbiology and process technology in order to achieve practical applications of the capabilities of micro-organisms, cell cultures, or parts of micro-organisms or cells. [13]

The emphasis on the integrated use of biological and technological disciplines is related to a concern, very marked around 1980, about the gap between the two clusters of disciplines. The Program Committee Biotechnology started out, in fact. with the aim of bridging this gap, and required both components in projects to be funded from their budget. When it turned out that an important segment of biological rescarch would then fall outside their scope, the requirement was relaxed.

The general concern to contribute to biotechnological innovation - the chairman of the Program Committee, in more exuberant moments, talked of the Netherlands becoming "the biotechnology delta of Europe" - was reflected in the way the Program Committee went about its task of articulating and implementing the priority. Three types of research were distinguished according to their position in an "innovation trajectory", and for each of them, specific measures were developed.

(1) Fundamental research relevant to biotechnology would be stimulated through the existing research council system, initially by having supplementary funding (30 percent of project costs would be financed through the biotechnology program), while in time, the full costs would have to be borne by the research councils themselves. A special committee, the Evaluation Committee Biotechnology, was created within the central organization of the research councils to judge proposals submitted for supplementary funding.

(2) Application-oriented research, which fits less easily into disciplinary organizations, was to be stimulated by the establishment of so-called " $M \mathrm{ul}$ tidisciplinaire dwarsuerhanden" (multi-disciplinary transverse organizational structures): within a university (sometimes two collaborating universities), different departments should participate in a collaborative venture in biotechnological research, with its own charter and with special support and protection from the central university board(s). Supplementary support from the Program Committee (up to $30 \%$ ). and the prospect of attracting outside money in general, would be the incentives for the universities.

(3) Applied research would be stimulated with the help of the new instrument of "Integral Applied Projects", collaborative ventures between a university and an industry (sometimes with government research institutes as a third partner). with the university research receiving additional support from the biotechnology program. An example (and the first such project, concluded in 1983) is the contract between Duphar and the University of Utrecht to develop vaccines against animal viruses with the help of recombinant-DNA technology.

During the regular program (1983-1988). the annual hudget of ahout 12 million Dutch guilders would be distributed over these three categories in the ratio $1: 3: 4$; the ratios reflect the increasing costs going from fundamental to applied research. In the first two years, the Program Committec was also able to allocate funds, although the program had not yet been formulated (until April 1982) or approved (until May 1983). A special budget had been allocated, out of which projects from catcgories (1) and (2) were co-financed. (Such a procedure has become quite common with Dutch science policy program committees: implementation starts before the program is fully articulated.)

Further details of the Dutch science policy scene and the activities of the Program Committee Biotechnology will be provided when necessary for the understanding of the evaluation of the effects of implementation. Our approach to the evaluation of effects on scientific research is based on a distinction between three levels at which a shift to biotechnological research and to the priorities of the Program Committee might occur: the micro-level of research decisions of individuals and research groups; the meso-level of research institutions, funding agencies and policy bodies, all with their own aims and vested interests; and the macro-level of overall trends (in science, as well as in the innovation race among industries and national states).

At the micro-level, it is the commitment of scientists to do research in biotechnology, and especially in the designated priority areas, that should be checked as the most important effect of 
implementation. To this end, a postal questionnaire was prepared and sent out in the fall of 1984, according to the Dillman-Nederhof method [6], [12], to a random sample of 336 biotechnological researchers. The net response was 76 percent (226 usable questionnaires), and this is estimated to form a 40 percent sample of the population of biotechnology relevant researchers in the Netherlands. The population consists of the members of the Dutch Biotechnological Association (380). corrected for non-biotechnologist members and for members working abroad, combined with the names of researchers in an inventory of current biotechnological research in the Netherlands [4]. Surprisingly, also for the Program Committee, which had taken the Dutch Biotechnological Association to be its primary target group, only 24 percent of the members of the Association appeared in the inventory. A possible explanation is the dominant technological and industrial-microbiological orientation of the Association, and the increasing relevance to biotechnology of much larger segments of the life sciences.

The questionnaire contained 69 (sometimes composite) questions, which asked for information about ongoing research, relations with industry, about knowledge and opinions on the Program Committee, perceptions of developments in biotechnology, and intentions for research in the near future and the importance of different considerations in such decisions. These last questions were based on the (modified) Fishbein-Ajzen model of intentional action [1], [7], a model which has been applied with success in other sectors, but never before to research decisions. One reason to introduce such a model was the timing of the evaluation study: half a year before the end of the term of office of the Program Committee. It would be important to know about the intentions for research by the end of $1985 /$ beginning of 1986 , in order to obtain the full picture of the effects of the committee's activities. Another reason was that such a model allows a better insight in the dynamics of research decisions, e.g.. whether attitudes toward fundamental or applied research are a dominant factor, or rather the work context and the views of team leaders and the institutional environment in general.

At the meso-level, the question is to what extent existing bodies and groups accommodate themselves to the new priority, and how far this priority becomes entrenched in the research system. Interviews with spokespeople from these bodies and groups, and analysis of documents, were sources of information. Again, a specific theoretical perspective was chosen: interorganizational linkages may be established because of new resource dependencies (funds, legitimation derived from following "official" priorities), and the network of linkages may become stabilized, so that it continues to exist and constrain (and enable) the different actors, also after the original incentives have disappeared. Such networks have been called "implementation structures" [9], and have been used to analyse energy research programs in Sweden [21]. In the latter study, the point was that earlier "implementation structures" (in this case, for nuclear energy research) would be an obstacle to the creation of new "implementation structures". Another aspect of the dynamics of implementation at the meso-level is that the "corporate actors" [10. p. 457] will introduce their own goals and interests into the "implementation structure", so that entrenchment may well entail a shift of goals from the original priority to one more suited to the corporate actors. In the case of biotechnology, the fact that more fundamental biological research has to be allowed into the program may be seen as the price to be paid to get the relevant corporate actors (e.g., some university departments and research councils) involved at all.

The macro-level cannot, in general, be manipulated by a program committee, so there is little use in checking for effects at this level. It is important, however, for the question of causality. In our case, it is a continuing problem in determining whether certain developments are a consequence of activities of the Program Committee Biotechnology, or of general trends, independently of the Committee. If one only wants to check whether certain effects obtain (e.g. more technology in biological research), it does not matter what the cause is. Lessons to be learned from the implementation, however, can only be drawn if there is a link between the activity and the effects.

One example of the difficulty of attributing causality is the increase in interdisciplinarity. According to the questionnaire data, there is increasing interaction between process technology, on the one hand, and molecular genetics, on the other hand, with the existing and substantial "bio-base" of microbiological and biochemical 
work (over the period 1981-1984). The fastest growing field is bioprocess engineering. This is exactly the trend visible in a core journal of biotechnology, Biotechnology and Bioengineering, over the period 1970-1979. [16] By the end of that decade. Dutch biotechnological research was published quite frequently in this journal. The international trend may therefore have influenced the interest in bioprocess engineering more than the objective of the Program Committee to have more interaction between biology and technology.

\section{Findings at the micro-level of researchers}

The Program Committee Biotechnology has been able to distribute money to researchers; the real question. naturally, is how far researchers have become committed to doing biotechnologyrelevant research (in general) and research in priority arcas in particular. Besides asking researchers in our sample directly about their intentions for 1985/1986, we also collected data on the dynamics of such decisions and on trends in the ficld.

The Program Committee had designated as priorities four areas of basic research (covering the disciplines mentioned in the definition of biotechnology) and four themes in application-oriented research (host-vector systems; somatic cell-hybridization; second-generation biological reactors and processes; product recovery). The distribution of intentions to do research within or outside these priority areas is shown in fig. 1 .

In application-oriented research, the universities show no clear preference for the priority themes: 43 percent of the university scientists in

\begin{tabular}{llll}
\hline & $\begin{array}{l}\text { (Highly) } \\
\text { probable }\end{array}$ & $\begin{array}{c}\text { Neutral } \\
\text { (Hlighly) } \\
\text { improbable }\end{array}$ \\
\hline $\begin{array}{l}\text { Intention to do application- } \\
\text { oriented research within }\end{array}$ & $52 \%$ & $11 \%$ & $37 \%$ \\
priority areas & & & \\
Idem, outside priority areas & $38 \%$ & $14 \%$ & $48 \%$ \\
Intention to do fundarnental & & & \\
rescarch within priority & & & \\
areas & $67 \%$ & $7 \%$ & $26 \%$ \\
Idem, outside priority arcas & $14 \%$ & $7 \%$ & $79 \%$ \\
\hline
\end{tabular}

Fig. L. Intentions of researchers to do research within or outside program priority arcas by late 1985/early 1986. the sample thought it (highly) probable that they would work on such themes, while 35 percent intended to work (instead or in addition) on application-oriented research outside the themes. In industry and in government laboratories the percentages of those intending to work on the priority themes are much higher: 70 and 62 percent respectively. Since the Program Committee had defined these themes with a view to their relevance to ongoing applied research, there may be a convergence of interest.

If it is acceptable that universities shift their research further in the direction of applications (an issue to which we will return below), these findings imply that commitment to the program priorities might be increased further. Biological researchers especially (a short-hand term indicating biochemists, molecular biologists, geneticists. microbiologists, immunologists, and other life scientists) would be a target group. The difference from technological researchers (biotechnologists, chemical technologists and other technologists and engineering scientists) is striking: the latter group $(N=39)$ intends to work on the application-oriented priority themes already $(81 \%)$, the former ( $N=126$ ) only for 47 percent. Intention to do basic research in the priority areas is high for biological researchers (76\%) - almost all fundamental research done by biological scientists in our population would fall under that designation - and appreciably lower for technologists (57\%), which is to be explained by the orientation towards application of technologists.

The differences between "biologists" and "technologists" deserve further discussion. The gap between the two clusters of disciplines, reflected in the differences in research style, in organizational forms and in disciplinary culture and attitudes, was considered to be a major stumbling block for the growth of biotechnology around 1980. On this account, the increasing collaboration between disciplines, including working in teams with both technologists and biologists, and the increasing interaction between the several scientific societies, is one of the successes of the Biotechnology Program. Questionnaire and interview data show that the change between 1980 and 1984 primarily consists in the mobilization of biologists towards technological issues and application, many of them in disciplines or institutions where such work was not common, and now ad- 
ding to the small core of industrial and environmental microbiologists and applied biochemists. The age distribution of the biologists in our sample has a broad top for 40-44 years. showing that the shifts were made by researchers already established in their disciplines. (This contrasts with the technologists, where a bi-modal age distribution was found: the old vanguard group promoting biotechnology already in the early 1970 s and now nearing 50 years of age. and the second generation trained by them.) The shift also appeared in the response to questions on ideas about application and on contacts with industry. Biologists (circa 1981) used to have fewer ideas about application than technologists, and although they now (1984) rate almost equal, the follow-up of such ideas is still much less. Contacts with industry are less intensive: 30 percent biologists, compared with 68 percent technologists, do appreciable amounts of contract research (for consultancy, the difference is less striking). Some further dala (e.g. on contacts with industry abroad) suggests a split within the group of biologists: about half being active in application-oriented relations, while the other half is not so involved, and limits itself to doing biological research that now turns out to have relevance for application.

Because the central program goal of the Committee was to stimulate more application-oriented research (and applied research, but this falls outside the scope of our study, also because this part of the program was implemented only at the end of the program period). further understanding of the dynamics of research decisions in this direction was sought by checking the variables that according to the Fishbein-Ajzen model of intentional action ([1], [7]) can influence the intentions to do research of a certain type by 1985/1986. The two major determinants of the intention to do application-oriented research were the reference environment of the researcher (primarily team leader, research director and director(s) of the institute) and earlier experience with applicationoriented research. There was no dependence on attitudes toward such research, as one might have thought, nor on considerations like the wish to do challenging research, investments made in current research, and financial advantages. that could in principle influence intentions [13]. For intentions to do fundamental research, the same dominance of reference environment was found, with in ad- dition some dependence on the attitude toward fundamental research. (Experience with fundamental research did not appear as a determinant, probably because almost all researchers would have had such experience during their training.) These results imply an important finding for the dynamics of research decisions: attitudes are much less important than reference environments in determining choices for fundamental and for application-oriented research. This may be related to the "collectivized" character of modern research [22]: it has also implications for the way policy priorities can be implemented. We shall come back to this point in section 5 .

A different way to make a possibly growing commitment to biotechnological research visible is to ask researchers about the extent of the biotechnological component in their work and about the importance they attached to it. On the average, the biotechnological component in the research of respondents has doubled in size between 1981 and late 1984, and is expected to increase further by 1985/1986. Figure 2 shows the distribution of different sizes of the biotechnological component in the sample. It is striking how the major shift is between little or no biotechnological component to an appreciable amount of biotechnology. (Retrospective distortion might occur, but tends to work in the opposite direction [8].) The hard core of researchers fully committed to biotechnology grows only slowly.

The picture that emerges fits with the earlier discussion of biologists shifting to biotechnologyrelevant research. It also raises the issuc of "band-wagon" effects: is biotechnology the new fashion, and are researchers relabeling ongoing research in order to share in the windfall? Such a relabeling may also distort the data presented here, as they are based on estimates from the scientists themselves; it is known, however, that mail surveys are much less an occasion for relabeling than presentations before audiences (including interviews). Apart from being a methodological problem in our study, relabeling is a continuing concern for science policy makers, who are afraid that their attempts are being undermined by such strategic behaviour of scientists. Therefore, we attempted to check for the extent of the phenomenon. First, we asked if respondents thought relabeling was widely spread, and then if they were involved in relabeling thernselves. The phenome- 


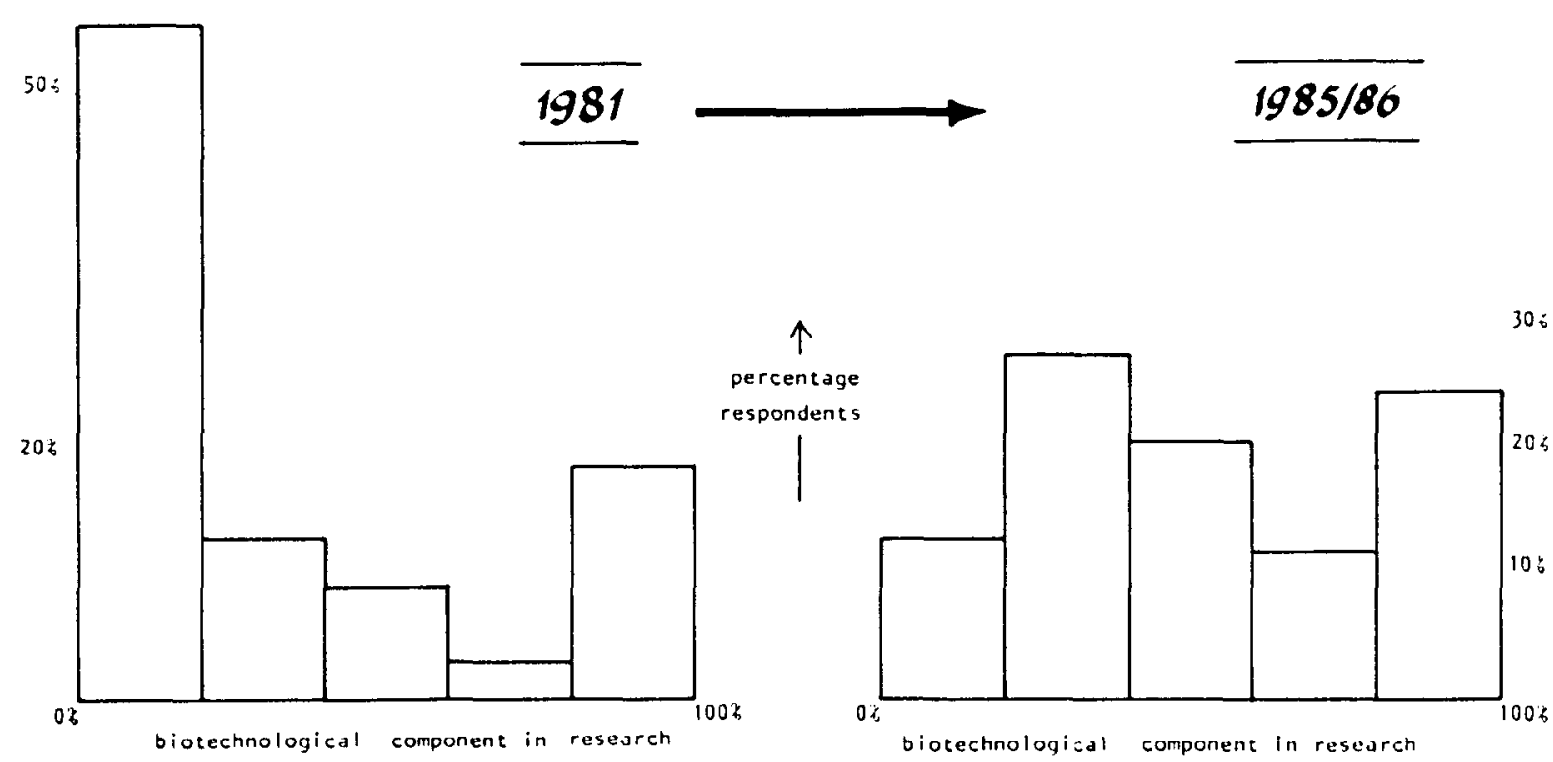

Fig. 2. Distribution of size of biotechnological component in research (retrospective estimates by respondents for 1981 . intentions for $1985 / 1986)$.

non was considered to be widespread (this was confirmed in the interviews), the own involvement in relabeling depended on how essential the biotechnological component was in the respondent's situation. If essential, little relabeling was reported. If less so (and this coincides with biotechnological components below 50 percent), there turn out to be two different groups: one exaggerates, the other is hesitant to attach the label 'biotechnology' and may well underestimate the extent of the biotechnological component.

Such a finding can be explained if relabeling occurs as sketched in fig. 3 (which introduces the unknown "real" biotechnological component!). It will be a function of both the actual extent of the biotechnological component, and of the strategy chosen by the scientist (up-labeling or down-labeling. one could say).

Two comments are in order. First, relabeling cannot be overcome, in spite of the justified concerns of policy makers. Screening of project proposals by knowledgeable reviewers certainly helps. Some of our interviewees held that, after a first wave of relabeling, screening, and especially the prospect of knowledgeable screening, had been sufficient to limit relabeling to relatively innocent majorizing of claims. In fact, scientific research can be relevant to a number of goals at the same time, and producing different labels for different audiences is part of a risk-spreading strategy [17]. A concrete example is provided by a project on microbial desulphurization of coal in the Technical University of Delft. It had been part of an earlier National Program to stimulate coal research, and was subsequently submitted (and accepted) for the biotechnology program. Furthermore, a label that has been attached to research for opportunistic reasons will still have some ef fects: some effort is made to retain credibility, while resources mobilized under the new label will also orient the research in the new direction. Indications of such processes happening could be found; however, it often takes a number of years before the effects of the new label become irreversible.

The policy implication of this analysis is that policy makers and implementators should not, after weeding out the worst cases, try to make screening ever more effective in reducing the amount of relabeling, but take the researchers up on their own labels, for instance by requiring accountability, and over a sufficiently long period of time. In the case of biotechnology in the Netherlands, four years appears to be enough in a few favourable situations, but another two years at least seems to be necessary to create stable 


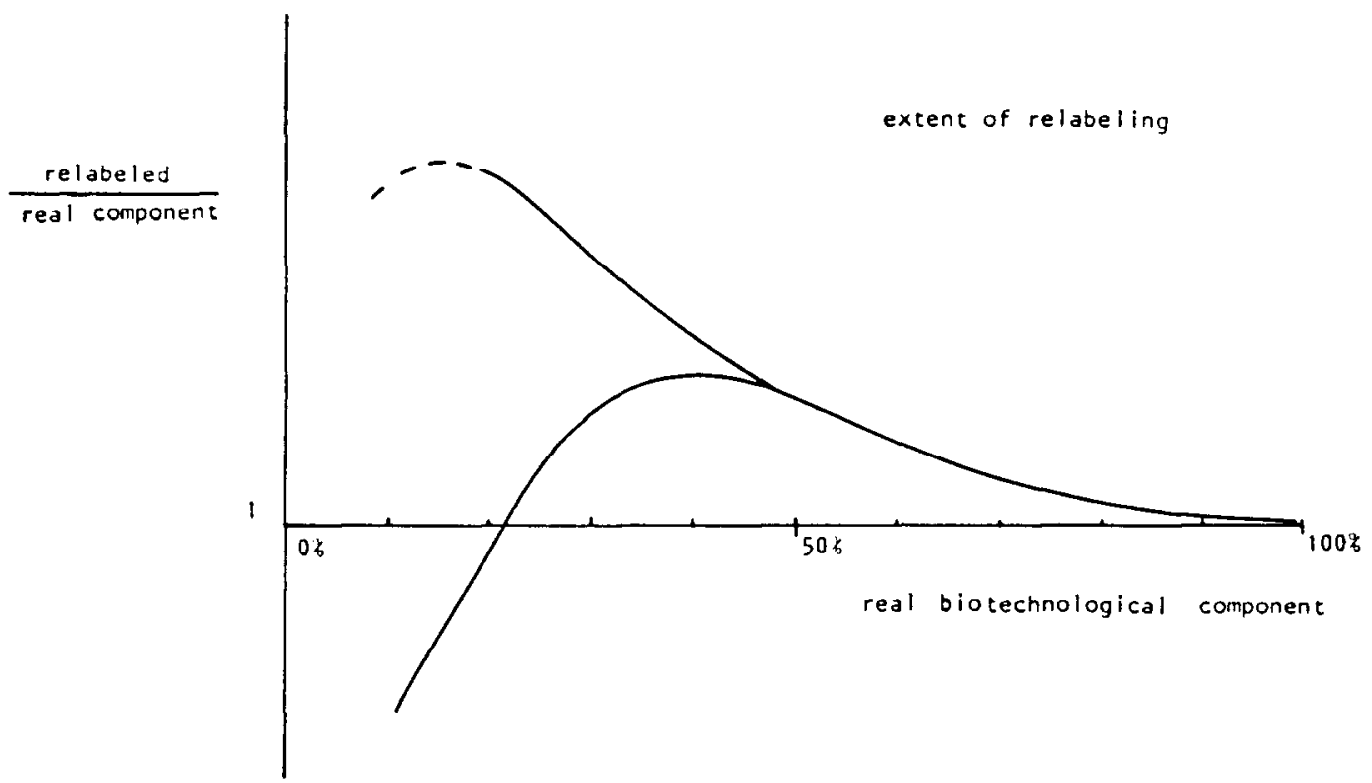

Fig. 3. Relabeling reseitrch as biotechnological.

commitments in general. More difficult to handle is the second comment: if our explanation of the findings (fig. 3) is valid, it implies that policy makers should also be concerned about researchers not recognizing the relevance of their work to the priorities (or not wanting to label it so). Unnecessary "down-labeling" can reduce the effectivity of implementation and is harder to spot and counteract than "up-labeling".

Commitment to the biotechnology program can also consist in knowledge of and identification with the program in general, independent of the details of one's own research. Forty-five percent of the respondents had good or very good knowledge, according to a knowledge scale constructed with the help of six questionnaire items. There is great overlap between this group and the 78 respondents with a biotechnological component of 60 percent or more in their research in 1984. This latter group contains practically all of the 41 respondents who say they feel quite involved with the program. Thus, there is a core group of heavily involved researchers. For such a group, the Program Commiltee is a more real presence than for more peripheral researchers, and they will be influenced more easily by the Committee (although not necessarily be more in agreement with it, as some examples show). Respondents from the core group rated the influence of the Committee in bringing about changes in the policy of the respondent's institution more highly; also, there is a correlation with frequent utilization of ideas about application.

The existence of a core group of involved and active researchers is important for the implementation of policy priorities, because they are, in general, senior researchers and have a say in their own groups and institutions. Creating such a group and maintaining its identification with the policy program may well count as a major objective for effective implementation, while the more visible allocation of funds is a means toward such a goal. An impression of the size of the different groups can be obtained by turning sample data into population data. The sample amounted to 40 percent of a population of members of the Dutch Biotechnological Association (an indicator of identification with biotechnology) and senior researchers in the 1983 inventory of Dutch biotechnological research (an indicator of involvement). The core group of our sample translates into the centre group, while the remainder will be periphery, but still close to the centre. Outside these groups, there are many more researchers doing work that is in some way relevant to biotechnology. The Program Committee and the Ministry of 

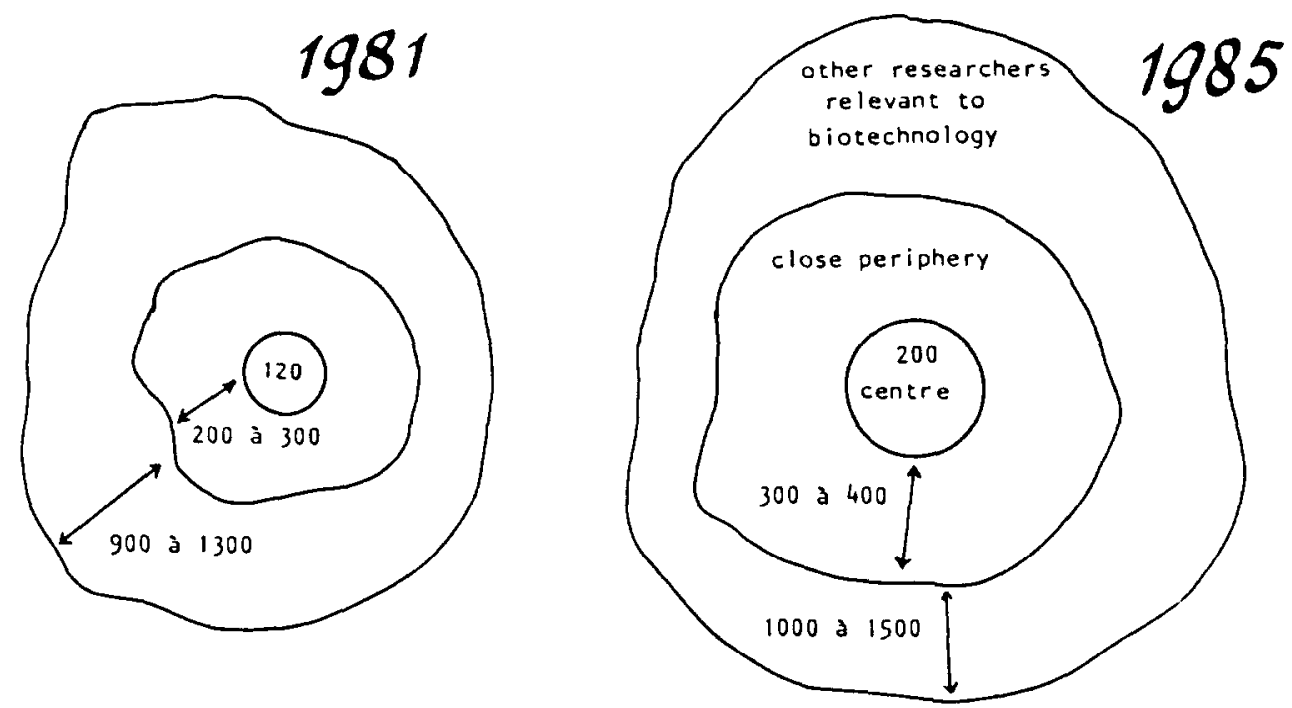

Fig. 4. Size of population of biotechnology-relevant researchers, 1981 and 1985.

Economic Affairs have put forward an estimate of 1500 to 2000 researchers in all. Thus, group sizes as in fig. 4 can be calculated; an estimate for the situation in 1981 is based on the data in fig. 2.

\section{Findings at the meso-level of institutions and} agencies

As already noted in section 2, the Program Committee faced a system in which actors like policy bodies, funding agencies and research institutions had already established their own domains and interests. Vertical lines predominate in this system (compare fig. 5), and there are clear blocks, often related to particular government ministries. An example is the National Council for Agricultural Research - formally a collaborative activity of all actors involved in agricultural research - with advisory and coordination tasks. At the same time, it is the well entrenched "implementation structure" [9] produced by the longstanding priority of rationalizing agriculture through research and advice, and concerned with defending this goal, as well as the jurisdiction over its domain. Another block (and, like the "green" block just mentioned, present in most Western industrialized countries) is connected with the goal of patronage for fundamental science: the research council system, funded by the Minister for
Education and Sciences. In the Netherlands, the scientists themselves are more strongly involved in the research councils than in most other countries, because they constitute standing panels to assess grant proposals and to discuss ongoing rescarch in their own areas.

When biotechnology became a priority, the actors in the research system, as well as some of the government ministries involved, started to survey this area and develop policy lines. The Ministries of Economic Affairs, of Agriculture and Fisheries, and of Housing. Physical Planning and Environmental Affairs, had reports written, while the $\mathrm{Na}$ tional Agricultural Research Council and the Central Organization of the Research Councils, as well as TNO, the big government supported Organization for Applied Research, established coordinating committees for biotechnology. The installation of the Program Committee Biotechnology (by the Minister of Education and Sciences, in his capacity of Minister of Science Policy, and the Minister of Economic Affairs) introduced a new, and "horizontal", actor into the system. The Ministries would now have to work through this committee, while the funding and policy bodies would have to defer to it, in so far as they would depend on it for funds and legitimation.

The Program Committee identified two tasks (apart from the writing of the program and specification of priorities): (1) forms and procedures to 


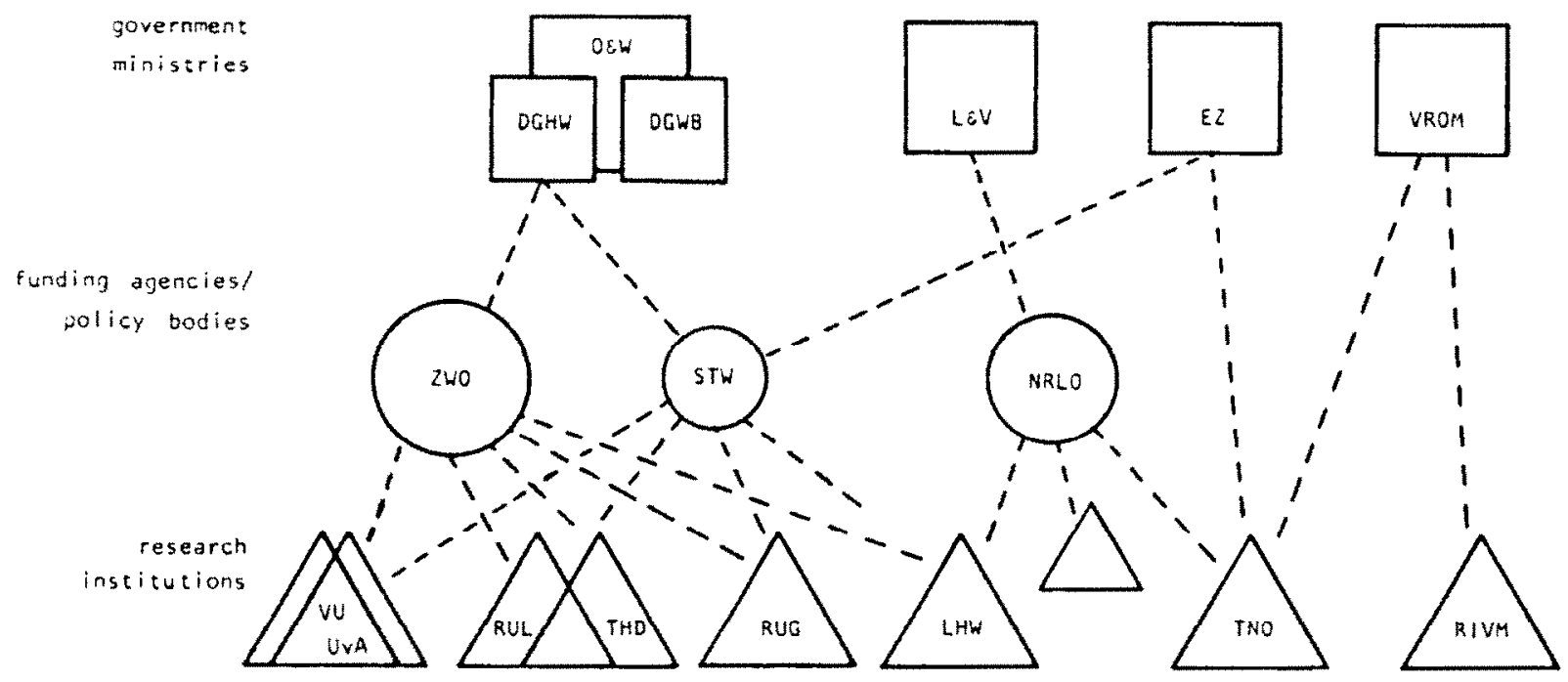

Fig 5 Science policy hodies and research institutions relevant to the Program Commillec Biotechnology, with lines of relationships indicated. DGHW - Office for Higher Education and Academic Research: DGWB $=$ Office of Science Policy: EZ = Ministry of Economic Affairs: LHW = Agricultural University Wageningen; L\&V - Ministry of Agriculture and Fisheriex; NRLO = National Council for Agricultural Research: O\&W * Ministry for Education and Sxiznces; RIVM = Statc lnstitute for Public llealth and Environmental Hygiene; RUG - State University Groningen; RUL - State University Leiden; STW - Foundation for Technical Sciences; THD - Technical University Delft: TNO - Organization for Applied Research: UvA - University of Amsterdam: VROM - Ministry of llousing. Physical Planning and Environmental Affairs; VU - Free University; ZWO - Central Organieation of the Research Councils.

distribute the funds made available for the stimulation of biotechnology had to be created, because existing institutions could not be relied upon to produce sufficient coordination by themselves; (2) allocation of funds and other activities had to fit into the policy framework that was being developed, and relationships with other bodies (hierarchical, consultative or collaborative) had to be forged to ensure coordination at the policy level. Gradually, the first task was realized through the distinction between three categories of research discussed in section 2, and a close collaboration between the Program Committee and the Evaluation Committe for Biotechnology of the Central Organization of the Research Councils. The latter committee, partly because of its composition (including an industrialist as chairman), identified strongly with the program and perspective developed by the Program Committee. and performed all sorts of assessments of research proposals for the Program Committee. It became a central node in the newly created horizontal network, the "mail box" for everyone who wanted support. In contrast, the relationship with other bodies (Foundation for Technical Sciences, Coor- dination Committet Biotechnology of the $\mathrm{Na}$ tional Agricultural Research Council) was strained, and only evolved into some working relationship by the end of the period.

Clearly, the second task was more difficult than the first. The problems were exacerbated by an ambiguity in the approach of the Program Com. miltee itself. On the one hand, it saw itself as the overarching committee, that would deal with the government ministries, establish overall policy, and monitor its execution. (As such, it was indeed appreciated after a time: in the field, the Program Committee was seen as an effective "product champion" for biotechnology, and as competent, both in biotechnology and in stimulating innovation.) On the other hand, it took upon itself to articulate and implement policies and priorities for industrial biotechnology, while more or less delegating agricultural and environmental biotechnology to existing bodies. Thus, it acted on the same level as these bodies. instead of above them. The actual work of the Program Committee was therefore biased towards (big) industry - this accusation was voiced a number of times - and relationships with other bodies remained ambigu- 
ous. At the end of the period, in May 1985. the Committee was dissolved, and the ambiguity was resolved by its being succeeded by two committees: an overarching Advisory Committee Biotechnology. and a special committee for industrial biotechnology. Most members of the Program Committee returned in one or the other of these two committees.

There are further and important effects to be checked at the meso-level, namely for the research institutions. Although universities, and especially big research institutions like TNO, the Organization for Applied Research, may play a role at the policy level, their primary function is that of intermediary between policy and the actual performance of research. This was reflected in the interviews. To trace an emerging "implementation structure" [9], spokespeople were asked whose opinions and actions they would take into account when deciding upon a course of action. Spokespeople from funding and policy bodies referred to each other and to the Program Committee, while spokespeople from research institutions started with work relationships. peer groups and competition with other research groups and other universities. The Program Commitice was only mentioned by those interviewees who were at the time actually negotiating with the Committee about institutional grants.

The impact of the Committee has been greater than suggested by interviewees, however, because the institutions and the interviewees use demarcations of biotechnology and priority areas designated by the Program Committee when arguing for their own plans and comparing themselves with competitors. The program and priorities developed by the Committee thus become, in effect, a forceful repertoire of legitimatory resources (even when they are used only rhetorically at first). The authority of the Committee derives not just from its being officially installed, but also depends on its being the main or exclusive source of material and legitimatory resources. This is reflected in the angry reaction of the Committee to the provision of special funds for biotechnology in the University of Amsterdam, by the Minister for Education and Sciences, in the course of a general reshuffling of university budgets, and without referring to the Program Committee. The Committee could not get the decision reversed, but then argued that the university should submit their plans for these funds to the Committee for approval. This was (more or less) agreed, and the University of Amsterdam often quoted the program priorities when presenting its plans for biotechnological research.

In general, the Program Committee has been able to shape biotechnological activities in the research institutions according to its plans. often by some accommodation to developments in the field and interests of the institutions. When the Committee started its work in 1981, the aim was already to establish just three centres for biotechnology: besides TNO. the Agricultural University Wageningen and the combination of the Technical University Delft and the University of Leiden were clear candidates having both technological and biological expertise and starting to integrate these disciplinary clusters. The third university-based centre was to be in the University of Groningen because of its tradition of applied microbiology and biochemistry. However, the combination of the University of Amsterdam and the Free University (located in Amsterdam) also claimed the status of a centre, a claim which was honoured in the Biotechnology Program drawn up in the spring of 1982. Each centre was to have (or maintain) a special focus, based on its expertise and on the wish of the Program Committe to partition the field systematically. For example, agricultural biotechnological research should now all be done in Wageningen, and conversely, other projects from this agricultural university, e.g. on biotechnological production of industrial chemicals, would not be honoured. (This example has been a bone of contention, which is connected not only with general resistance of scientists to interventions in their research decisions, but also with the overall transformations in bio-agricultural research, where the new approaches are being explored outside the traditional institutions for agricultural research.)

The designation of centres with specific focuses has speeded up the process of entrenchment of the biotechnology program in the research system. It provided a competitive advantage to research groups that were able to fit in with the priorities, and university boards. anxious to create an attractive profile for their university, tended to stimulate their biological and technological researchers in this direction. When the Program Committee started to make support available for the so-called Multidisciplinaire dwarsverbanden (see section 2) 
in the course of 1984, there were already definite plans from one centre, and some outlines of proposals in the other centres. At the same time, two modifications were introduced. One was the acceptance of a further centre. the University of Utrecht. with a focus on medical biotechnology. The Program Committee had neglected this area. while the University of Utrecht. in spite of its definite expertise and the support it received for its contract to develop vaccine preparation methods for the Duphar company, had not bothered to present itself as a centre. When the Program Committee organized a round of talks about the program and especially the Multidisciplinaire dwarsverbanden with all universities in the summer of 1984. perceptions on both sides changed, and the University of Utrecht started a (successful) catching up operation.

The second modification derives from the general effort of the Program Committec to articulate its priorities and to make biotechnological research more responsive to industrial needs. To this end, interviews were held with eight major companies on a strictly confidential basis, and the results were transformed into preferred themes of research, e.g. more work with yeasts and Bacillus, importance of enzyme technology and protein engineering. (At a later stage, also smaller firms were interviewed.) A new element was that the companies were also asked to identify good research teams in areas relevant to brotechnology. The Program Committee then published the list of preferred themes of research, and specified for each theme the core groups identified by industry. The universities and other research institutions only had to fill in the details, one could say.

Effects of this step in the articulation of priorities can be traced in the program, as well as with the research institutions. New priorities were added to the program (e.g. protein engineering), while the research institutions generally followed the outlines given by the Program Committee. There was some grumbling by researchers about the (big) industry bias: "I refuse to become a branch of Gist-Brocades (a major biotechnology company)". Also, all institutions wanted to work on preferred themes (e.g. yeasts), in spite of the selections set out by the Committee. Still, there is some ground in the view of the Committee that their approach to focus university research is a breakthrough. Because priorities are now linked to identifiable performers of research and concrete users, one may expect that horizontal relationships will evolve and become entrenched. i.e. continue without the active stimulation by a Program Committee.

From these findings, it appears that the definite shift to application-oriented research in the universities discussed in the previous section is coupled with organizational and policy transformations, including stronger links with industry and other users of biotechnological research. Respondents perceived the activities of the Program Committee as one determinant of the shift in academic culture to a greater acceptance of applied research and links with industry. Concerns have been voiced, also in the Netherlands, about the dangers of this development for the position of university research and for the neglect of fundamental research in the area. Many respondents (as well as interviewees) shared this concern, but thought the problems manageable and/or not yet dangerous. An intriguing finding is that industrial respondents (and also respondents from government research institutions) thought the dangers greater than university respondents (only a quarter saw dangers). This may be connected with the typical industry perspective of a division of labour in research, where universities have the responsibility to do fundamental research. In the universities, on the other hand, the cornucopian vision of science and the possibilities for expansion are dominant considerations, while concerns about dangers may be repressed in order to follow the band-wagon.

\section{Implementation strategy and the dynamics of} orientation of research to priorities

Although the observed effects in biotechnology-related research in the Netherlands cannot always be attributed unambiguously to the activities of the Program Committee, these certainly have had an impact, and the goals of the original priority would not, or not as rapidly, have been reached without them. This makes it relevant to assess the value of the strategy of implementation followed by the Committee: with a clear picture of what it wanted to achieve, they orchestrated its implementation while at the same time accommodating to interests and obstacles in the research system. This might be a model for the middle 
course between dirigism and laissez-faire. Such an evaluation is bound up with a consideration of the dynamics of scientific research in a context of priority setting.

In general, one should realize that government ministries often have no specific priorities for science. They commission particular research projects relevant to their goals, and at times try to create programmatic coherence among them. Apart from that, ministries generally have a portfolio of themes and objects of research that they are interested in and willing to support if the occasion arises. The government ministry of science policy is a special case, because their portfolio of priorities is the main thing, and one of the justifications for its existence. In the Netherlands, the Office of Science Policy (of the Minister of Education and Sciences in his capacity of Minister of Science Policy) has created such a portfolio explicitly. Implementation of a priority, however, requires further articulation, which cannot be achieved without involvement of the relevant scientific and technological fields (and other relevant actors). In the Netherlands, special organizations. so-called sectoral councils, address the articulation of priorities and the formulation of research policy in broad areas of government concern on a continuing basis. The device of a program committec, however, is more effective in particular cases, provided it has sufficient autonomy to orchestrate the implementation. This follows from studies of implementation of policy in general, which emphasize the importance of having a "fixer" to continually repair and add to the rules of the implementation game that has been set out by the government [2].

In the case of science policy, it is important that a program committee does not lack legitimation with regard to the scientific community. On the other hand, committee members should identify sufficiently with the original priority to avoid large goal-shifts. Thus, the selection of committee members becomes a first step in the implementation, and the major one as far as the original policy maker is concerned. In the case of the priority for biotechnology in the Netherlands, the search was for scientists of sufficient standing within their own community, prepared to take an activist approach, and interested in the application of biotechnology. The selection took a long time. also because important sectors and actors had to be represented. In fact, the committee was expanded after its original establishment in May 1981, first with a member from Gist-Brocades (the major presence in Dutch industrial biotechnological research), later with a member representing the National Agricultural Research Council. The activism required by the necessity to "fix" the implementation game (in this case also in another sense: many of the rules had to be developed by the committee itself) was assured not only through the attitudes of the members (especially chairman and secretary), but also because the committee saw itself as a product champion for biotechnology. Many members belonged to the small core group of biotechnologists in the Netherlands that had founded the Dutch Biotechnological Association in 1978, and worked to create a professional identity for biotechnology. The global priority for biotechnology was in line with their own views, and left them enough room to specify themes and procedures as they saw fit.

From the top down, the situation was set for suceessful implementation. From the bottom up, there was at first some reluctance. As discussed in section 3, many hiologists had little experience with application-oriented research, nor a great wish to acquire it. At the first presentation of the plans of the Program Committec to the scientific and technological community (October 1981), concerns were voiced (also by the (bio)technologists) about the additional bureaucracy proposed. Four years later, many of those scientists and technologists were working on priority areas and they, as well as their institutions, had adapted to the new organizational forms introduced in the research system. It is important to understand the dynamics of such a shift, because implementors have to deal with it and modulate it in order to achieve their aims.

Two points can be made on the basis of our study. The first derives from our finding that researchers themselves attribute major influence on research decisions during the last four years (the years during which the biotechnological component in their research increased, see fig. 2) to their institution and its policy, with their own research interests coming second. Activities of the Program Committee were considered to be least influential (of a list of eight possibilities). As fig. 6 indicates, the rank order of perceived influences on past research decisions was different in differ- 


\begin{tabular}{llll}
\hline & \multicolumn{3}{c}{ University Industry Government } \\
& $(57 \%)$ & $(215)$ & $(18 \%)$ \\
\hline 1. Policy of own institution & 3 & 1 & 1 \\
2. Own research interest & 1 & 3 & 3 to 2 \\
3. International science & 2 & 4 & 2103 \\
4. Concrete external questions 4 & 2 & 4103 \\
\hline
\end{tabular}

Fig. 6. Rank order of factors perceived to influence research decisions in the period 1981-1984, for respondents from different types of institutions (percentages indicate fraction in sample). Rankings for respondents from government research institutions cannot be aggregated unequivocally.

ent sectors, but in all cases there is a large gap between the four quoted factors and the other. more policy-related factors. The influence of policy is exerted indirectly, through the decisions of the research institutions (see fig. 7). Examples of the influence of the Program Committee on the institutions have been quoted in the previous section. Their discussion indicated that influence could often only be achieved by some accommodation to the interests of these institutions. For implementation strategy, these findings and interpretations imply that making funds available for research projects in a certain area will only create commitments if funding is coupled with organizational and policy changes in the research institutions

The second point derives from an analysis of research decisions in terms of strategic action. Researchers take risks when they decide to invest in new projects. and evaluate benefits and risks in terms of their own skills and strategies. developments in the field. actual and potential activities of competitors, and expectations about possible support and other resources. Decision making is also strategic for corporate actors like research institutions and funding bodies. although considerations will differ (e.g. institutional charter, profile, turf). The presence of a biotechnology program will shift the assessment of risks and benefits; its implementation may therefore be directed to judicious placing of funds and other resources. An immediate consequence of the strategic perspective is that the promise of possible funds will often be a stronger incentive than the actual allocation of funds: once the money has been obtained, the efforts of the scientists will be geared to the mobilization of new resources.

There is a further implication: since access to

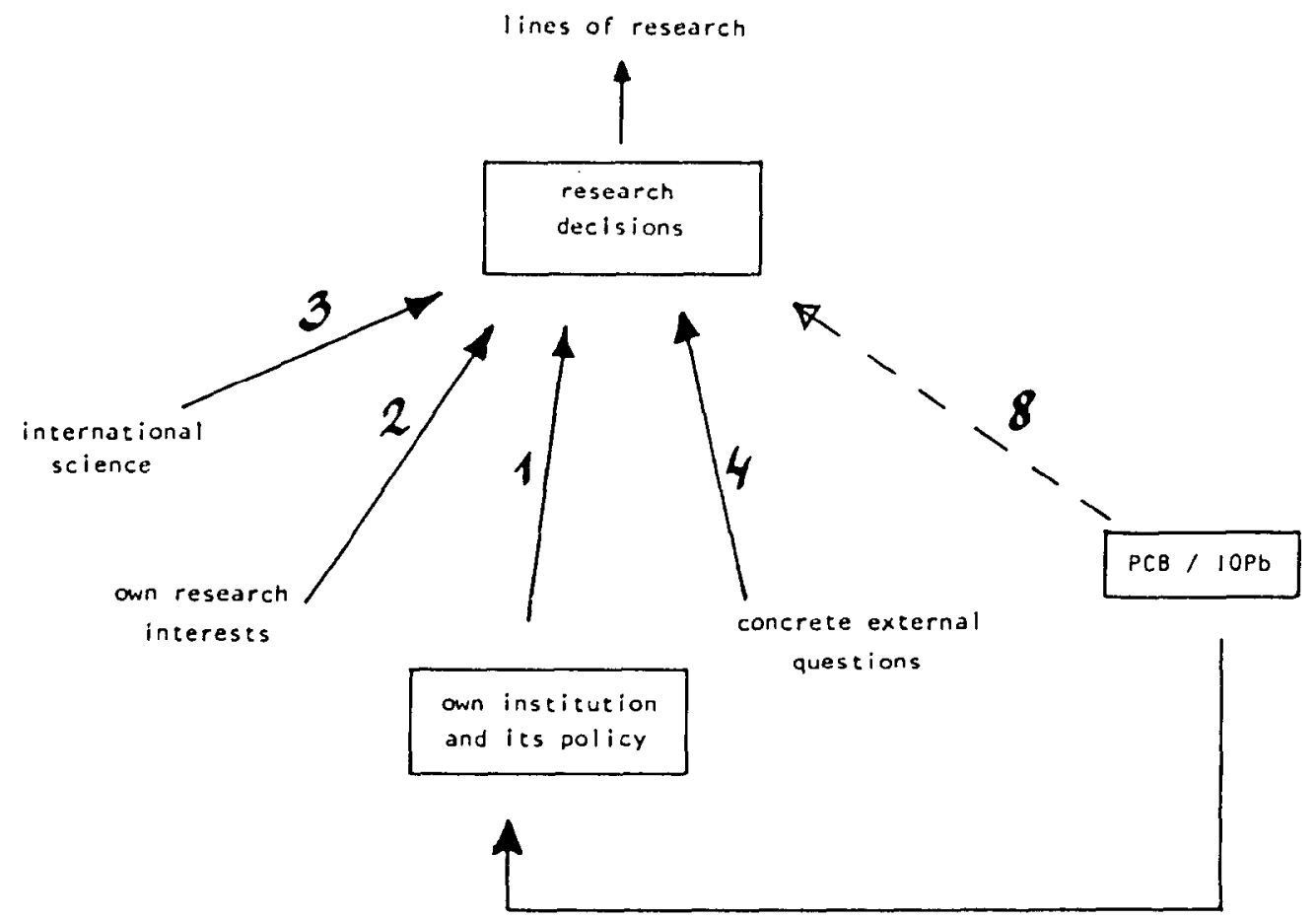

Fig. 7. Perceived influence on research decisions. 1981-1984. 
the resources provided by a new policy program is not unrestricted - one has to do certain kinds of research, for instance, to qualify - it is not just the direct "costs" of the resources that determines the evaluations of the actors. The "market" of opportunities for resources is an imperfect market - and since the actors know this. they act to secure a privileged position in the opportunity structure. (Terminology adapted from [10].) This explains part of the band-wagon effect. For example, biotechnological research focusing on yeast has gradually become more important [18], and all biotech. nologists will be aware of the possibilities. When yeasts were to be one of the preferred themes in the further specification of the program (see section 4). more researchers than the Program Committee had envisaged decided to invest in (proposals for) yeast research: they wanted to maintain access to this part of the opportunity structure.

The same type of argument applies to the decisions of biologists and technologists to become involved at all with biotechnology, or with the kind of biotechnology emphasized by the Program Committec. They see an opportunity structure in the making, and some actors already in a privileged position (in our case, an example would be the three centres envisaged originally). At first, only some of the biologists and technologists that could make the switch (in terms of skills and institutional position) do so. But with each switch, the opportunity structure for biotechnology becomes stronger, and the choice for the others more clear cut. At some point, a "critical mass" is reached, and the band-wagon starts to ride. Within a brief period, "everybody" would have started to do biotechnology - or have turned away definitely. In terms of the picture shown in figs. 2 and 4. there would not be a logistic growth curve of biotechnologists and biotechnological components in research, but a slowly accelerating ascent, followed by a step function to almost the saturation level. As was argued in section 3, while some of these switches may start out as relabeling, they will become real if the opportunity structure is maintained long enough.

To be effective, the implementor has to play on the dynamics of strategic decision making, has to orchestrate the band-wagon effect as it were. The Program Committee has done so, partly intuitively, partly by trial, error and correction, and obviously helped on its way by the world-wide interest in and advances of hiotechnology. It has also paid a lot of attention to the relations between the different corporate actors and to the creation and stabilization of network linkages, which are other necessary aspects of successful implementation according to our analysis. Finally, the Program Committee has sought publicity for biotechnology and for its program goals to an extent that is not always found in science policy. Even if this derives from its stance of "product champion" for biotechnology, the effect has been to create "credibility pressure": researchers were forced to ask themselves why they were not part of the program, and if they did not raise the issue, it would be brought up by the board of their research institution. Obviously, publicity forms a dangerous tactic: it may backfire if it is perceived as just public relations. In fact, such reactions were heard, and it was respect for the competence of the committee members that saved them. (The other danger is that the committee will raise too high expectations about their efforts with policy makers and the public; again, a matter of finding the right balance.)

These brief considerations of implementation strategies and the dynamics of orientation to policy priorities, informed by the experiences of the Dutch Program Committe Biotechnology, show that there is much more to the implementation of priorities than top-down programming or putting one's hopes on proposal pressure. The middle course between these two extremes has been followed in practice in many cases already, and with effect, especially if the possibilities to exert leverage were exploited. In this article we have shown that systematic evaluation and analysis of experiences leads to potentially generalizable insights, and thus allows transfer to other cases.

\section{Acknowledgements}

The study of the effects on scientific research of the stimulation of biotechnology in the Netherlands was commissioned by the Office of Science Policy of the Ministry of Education and Sciences, and performed by the Leiden Institute of Social Policy Research (LISBON). Some of the ideas about implementation strategies presented in this article were developed in the framework of a 
project of the Department of Science Dynamics. University of Amsterdam. and the Dutch Science Policy Advisory Council (The Hague) on the implementation of science policy priorities.

\section{References}

[1) 1. Ajzen and M. Fishbcin. Understanding Atritudes and Predicting Social Behatior (Prentice Hall, Englewood Cliffs. NJ. (1980).

[2] E. Bardach. The Implementation Game: What Happens Affer a Bill Becomes a Law? (MIT Press, Cambridge. MA. 1477).

[3] Alan T. Bull, Geofrey Holt and Malcolm D. Lilly. Biotechnolog. International Trends and Perspectices (OECD. Paris. 1982\}.

[4] CiLO. Current Bintechnological Resecarch in the Netherlands, 1983 (CILO. The Hague, 1983).

[5] Wolfgang van den Dacle. Wolfgang Krohn and Peter Weingart (eds.). Geplante Forschung. Vergleichende Studien isher den tinfluss politischer Programme auf dic Wissonschaftsentwicklung (Suhrkamp. Frankfurt a/Main. 1979).

(6) D.A. Dillman. Mail and Telephome Suregys: The Total Design Lethed (Wiley. New York, 1978).

(7) M. Fishbein and I. Ajzen, Belicf. Arritude; Interniom and Bcharver (Addison-Wesley, Reading. MA. 1975).

(8) S.T. Fiske and S.E. Taylor, Socod Cognition (AddisonWeslcy. Reading, MA, 1984).

[9] B. H ljern and D.O. Porter, Implementation Structures: A New Unit of Administrative Analysis, Organization Srudies 2 (1981) $211-227$.

(10) Edward O. Laumann. Joseph Galaskicwicz and Petcr V. Marsden, Community Structure as Interorganizational
Linkages. Annual Retitu of Soctology 4 (1978) 455-484.

[11] Robert R. van der Meer and Hens ten Hoopen (eds.). The Vetherlands. Busy in Botechnology (Staatsuitgeverij. The Hague, 1985).

[12] A.J. Nederhof. Beter Onderzoch (VUGA, The Hague, 1981).

[13] Anton J. Nederhof and Arie Rip. Research Decisions: Doing Your Own Thing? (in preparation)

[14] Programmacommissie Biotechnologie. Innotatieprogramma Biotechnologie. Kader. hoofalijnen, operationed plan (Staatsuitgeverij, The Hague. 1982).

[15] Arie Rip. A Cognitive Approach to Science Policy. Research Policy 10 (1981) 294-311.

[16] Arie Rip. Indicatoren van ontwikkelingen in de biotechnologie. Bedrijskunde 55 (1983) 137-144.

[17] Arie Rip, Mobilising Resources Through Texts, in: Michel Callon. John Law and Arie Rip (eds.), Mapping the $D_{Y}$. namics of Science and Texhnolog. (Macmillan, London, 1986).

[18] A. Rip and J.P. Courtial, Co-Word Maps of Biolechnology: An example of Cognitive Scientometrics, Scientumetrics 6 (1984) $381-400$.

[19] A. Rip and A.J. Nederhof. Sumedering ean de hiotechno.

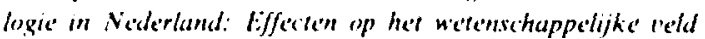
(Stalatsuitgeverij. The Hague, 1985). (A brief summary is in $[11, \mathrm{pp} .19-21]$.)

[20] Wolf Schafer (cd.). Findization in Science. The Social Oriensution of Scientific Progress (Reidel, Dordreche, 1983).

[21] Bjisrn Wittrock. Stcfan Lindstrom and Kent Zetterberg. Implementation Beyond Hicrarchy: Swedish Energy Rescarch Policy, Europessn Sournal of Political Research 10 (1982) $131-143$.

122] J.M. Ziman, The Collectivization of Science (Bernal Lec. ture 1983). Proce'tedings Royal Society 8219 (1983) 1-19. 